\title{
Education for Digital Earth
}

\author{
Robert Vogler, Alfons Koller and \\ Karl Donert (Eds.)
}
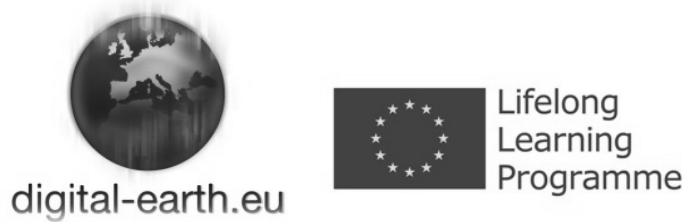

This publication is part of the EU-funded Comenius network digitalearth.eu 510010-LLP-1-2010-1-AT-COMENIUS-CNW. It reflects the views only of the authors, and the Commission cannot be held responsible for any use which may be made of the information contained therein. 